\title{
ANALISIS AKULTURASI DAKWAH PADA MASA KENABIAN MUHAMMAD
}

\section{Wawan Sopiyan, Mukhlis, Solimin}

STAI Bumi Silampari Lubuklingau, Indonesia wawansopiyanpasundan@gmail.com

muklisjogoboyo@gmail.com,soliminajo@gmail.com

\begin{tabular}{ll}
\hline & Abstrak \\
\hline Article History & In highlighting the portrait of \\
Received: & Da'wah practiced by the Messenger \\
Revised: & of Allah in several periods, it can be \\
Accepted: & said that the missionary mission that \\
\hline Keywords: & was being carried out at that time \\
Akulturasi, Dakwah, masa & was not an easy activity, in the \\
Kenabian Muhammad & course of Islamic history recorded, \\
& that the da'wah carried out by \\
& Muhammad, encountered many \\
& obstacles and obstacles, due to \\
& internal conditions humanity and the \\
& aqeedah of Arab society in general \\
& are in a state that is far from the \\
& teachings that Muhammad is \\
& broadcasting. Therefore, the da'wah \\
& process that will be applied really \\
& requires a mature strategy, \\
& especially the condition of the \\
& people who are accustomed to doing \\
& past activities and practices such as \\
& consuming alcohol, gambling, \\
fighting power, adultery, adultery to \\
murder.
\end{tabular}

\section{Pendahuluan}

Dakwah secara bahasa dipahami sebagai suatu proses transpormasi pesan-pesan tertentu yang berupa kecenderungan untuk mengajak atau seruan dengan rujukan agar orang lain memenuhi ajakan tersebut. Dari segi termenologi, dakwah dipahami secara popular sebagai aktivitas mengajak manusia dengan cara bijaksana kepada jalan yang benar sesuai dengan perintah Allah, untuk keselamatan dan kebahagiaan mereka di dunia dan akhirat. dengan 
demikian, Dakwah dapat kita pahami sebagai jalan menuju islam, beberapa relevansi ayat seperti Al-Imran 19 telah menguraikan mengenai posisi penting dakwah dalam Islam (Siti Muriah: 2-3).

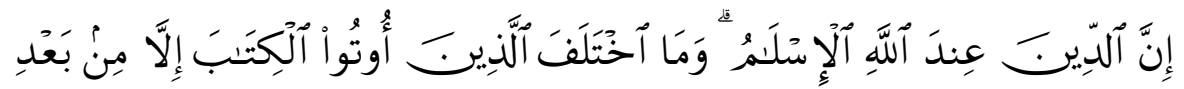

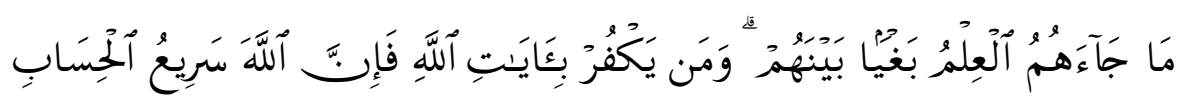

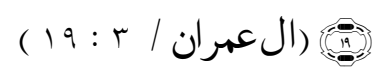

Terjemahannya : Sesungguhnya agama (yang diridhai) disisi Allah hanyalah Islam. tiada berselisih orang-orang yang telah diberi Al-Kitab kecuali sesudah datang pengetahuan kepada mereka, karena kedengkian (yang ada) diantara mereka. Barang siapa yang kafir terhadap ayat-ayat Allah. Maka sesungguhnya Allah sangat cepat hisab-Nya (Depag RI:2013).

Pada permulaan kenabiannya, Muhammad Rasulullah pada periode Mekah, menyusun berbagai strategi dan ide-ide pokok tentang aplikasi Islam, kemudian tahap selanjutnya berupaya memperkenalkan dan mengajarkan masalah-masalah ibadah, perundang-undangan sosial hingga masalah ketentuan pidana yang berlandaskan hukum al-Qur'an yang diterapkan oleh Islam. Dari sisi lain, dakwah dalam masyarakat Islam dipahami sebagai upaya setiap muslim untuk merealisasikan fungsi kerahmatan. Fungsi kerisalahan berarti upaya meneruskan tugas yang diwariskan oleh Muhammad Rasulullah, yang patut dijadikan tauladan dalam segala budi pekertinya di setiap zaman. Berkat berbagai upaya dan perjuangan dakwahnya dalam menyebarkan agama Islam benar-benar berimplikasi dalam membawa rahmat bagi seluruh alam, dan bahkan diakui membangun tatanan dunia baru yang tenteram dan damai. Muhammad, sebelum menerima risalah, yang penuh dengan berbagai pengalaman, baik sewaktu berada di Negeri Syam pada usia 12 tahun untuk mengikuti pamannya Abu Thalib untuk berniaga ke negeri tersebut, maupun sewaktu beliau ke negeri Syam kedua kalinya pada usia 25 tahun untuk mengawal dan menjalankan dagangannya Khadijah, dapat diketahui bahwa masa itu seakan-akan Rasulullah melakukan observasi, karena adanya pergaulan dengan berbagai bangsa dan suku pada saat terlibat dalam dunia perniagaan, sejarah 
Islam mencatat bahwa dengan profesi ini membuat Muhammad Rasulullah banyak memperoleh informasi, data, fakta tentang agama, adat istiadat, hingga potret kehidupan sesuatu bangsa dengan penuh keragaman. Menjelang Risalah datang sebagai titik mula kenabiannya, Muhammad Rasulullah, melakukan Tahanus di Gua Hira untuk setiap tahunnya sepanjang bulan Ramadhan. Di tempat itu beliau menenangkan fikiran dan mengheningkan cipta, jauh dari hiruk pikuk dunia untuk mencari kebenaran mutlak. (Yahyah Omar: 1979)

Pikiran dan konsekuensi jiwanya terlah dibenahi dengan perencanaan matang untuk menegakkan kebenaran di tengah-tengah kemerosotan nilai nilai kemanusiaan pada kaum dan masyarakat Arab kala itu. Ketika Muhammad Rasulullah, pertama kali menyebarkan agama Islam pada kawasan masyarakat Arab pada masa itu, kondisi sosial dikenal sebagai kondisi dalam suasana kejahiliahan. Umumnya masyarakat Arab pada masa itu, memiliki moralitas yang bobrok, peradaban sosial masyarakat Arab kala itu telah kehilangan nilai-nilai budi dan kemanusiaan, bahkan para ahlih sejarah mencatat bahwah masyarakat arab kala itu kerap mencampur-adukan kebenaran dengan kebatilan, fenomena menyembah berhala, percaya terhadap para penyihir hingga praktik tradisi-tradisi yang tidak patut menyebar luas ditengah masyarakat. (Ramadhan: 1999) Dalam kondisi sosial masyarakat Arab yang seperti itulah kemudian Muhammad di utus untuk menyempurnakan aqidah pada periode Mekah. Dalam menjalankan misinya, beberapa Langkah dan strategi dakwah Islam pada mula-mula di prioritaskan kepada kaum kerabat yang terdekat kemudian kepada para sahabat yang diyakini nanti akan dapat membantu dan mendukung pengikutnya yang setia, serta langkah yang digunakan dalam berdakwah yang dimulainya dengan cara sembunyi-sembunyi dan kemudian secara terang-terangan secara bertahap dan konsisten. Dalam upaya ini, berbagai upaya dengan metode yang sesuai dengan misi utama Rasulullah untuk mensukseskan tujuan tersebut. Beberapa catatan sejarah menjelaskan bahwah dakwah memiliki usia panjang, sepanjang usia kehidupan manusia di bumi. Pada aspek lainnya, telah membuktikan bahwah dakwah juga menjadi program dan misi utama dalam menyampaikan risalah Islam dalam perkembangannya.

Dalam menyoroti potret Dakwah yang dipraktikan Rasulullah pada beberapa periode, dapat dikatakan bahwa misi dakwah yang 
tengah dijalankan kala itu bukan merupakan sesuatu aktivitas yang mudah, dalam perjalanan sejarah Islam mencatat, bahwa dakwah yang dilakukan Muhammad, menemui banyak sekali hambatan dan rintangan, karena kondisi internal kemanusiaan maupun aqidah masyarakat arab pada umumnya sedang berada dalam keadaan yang jauh menyimpang dari ajaran yang sedang Muhammad syiarkan. Oleh karna itu, proses dakwah yang akan diterapkan, benar-benar membutuhkan startegi yang matang, telebih kondisi masyarakat yang notabenenya telah terbiasa melakukan aktivitas dan praktik masa lampau seperti mengkonsumsi Miras, perjudian, adu kekuatan, zinah, hingga fenomena pembunuhan. Di sinilah peran Muhammad kala itu dalam melakukan misi mengajarkan aqidah pada periode Mekah, beliau banyak memiliki beberapa strategi yang digunakan dalam menyampaikan ajaran Ilahi, seperti nasehat untuk bertakwa dan membersihkan diri, belajar dan beramal baik serta mencegah kemungkaran. Kedudukan Muhammad, sebagai pemberi kabar gembira, mentranspormasikan nilai agama islam untuk mengajak masyarakat agar meninggalkan tradisi sosial budaya yang mengandung perbuatan yang jahiliyah, upaya tela'ah terhadap literatur sejarah dakwah yang dipraktikan oleh Muhammad Rasulullah, merupakan jawaban terhadap diskursus sosial Islam yang relevan.

\section{Metode Penelitian}

Berdasarkan jenisnya Karya tulis ini merupakan kajian pustaka atau Library Reseach, sebagaimana yang diutarakan oleh Prasetya irawan bahwah, Library Reseach ini merupakan Penelitian yang datanya diambil dari sebagian atau seluruhnya dari perpustakaan. Contohnya artikel ilmiah, laporan, buku-buku, majalah dan lainlainya. (Prasetya Irawan: 1999) Ditinjau dari sumber data yang digunakan dalam penelitian ini mencakupi sumber primer, skunder dan tersier. Sumber data Primer dalam tulisan ini di ambil dari AlQur'an dan Hadits, dan buku Sirah Nabawiyah, Ilmu Dakwah, Ensiklopedia Islam, Logika dan Prosedur Penelitian, yang mendukung penelitian tentang aspek dakwah Rasulullah Muhammad dalam mengimplementasikan dakwah, terutama periode Mekah. Sedangkan sumber data sekunder di ambil dari segala sumber data yang berasal dari skripsi, skripsi Sujarwo, skripsi Muhammad Haezan yang memiliki berhubungan terhadap objek kajian maupun 
pembahasan dalam penelitian ini. Adapun sumber data tersier, di ambil dari karya ilmiah, atau sumber-sumber yang mendukung penelitian ini termasuk data-data on-line dari internet.

Ditinjau dari metode pengumpulan data yang digunakan dalam penelitian ini, mencakup beberapa aspek yaitu metode dokumentasi dengan cara mengumpulkan data, seperti arsip-arsip dan termasuk juga buku-buku tentang pendapat, teori, dalil atau hukumhukum, dengan menelaah literatur kepustakaan yang dianggap memiliki hubungan dengan masalah yangg diteliti (margono, 2007:36). Sedangkan dalam melakukan analisa terhadap data yang telah dikumpulkan dan diklasifikasikan adalah dengan menggunakan analisa deskriptif kualitatif yaitu pencarian data dan fakta dengan interpretasi yang tepat dapat menggunakan kerangka berfikir deduktif yaitu menggunakan pemikiran yang bersifat umum untuk selanjutnya dispesifikasikan secara khusus. Sedangkan berfikir induktif adalah kerangka berfikir dari fakta-fakta atau peristiwa khusus lalu ditarik ke umum.

\section{Tinjauan Pustaka}

Berdasarkan tinjauan, penulis menemukan beberapa sumber buku-buku yang menjadi rujukan dan judul yang mempunyai hubungan terhadap pokok pembahasan yang disusun, dalam hal ini penulis mengambil acuan baik dari sumber buku dan tulisan ilmiah sebagai pembanding. Buku-buku yang relevan membicarakan tentang aspek dakwah Rasulullah Muhammad dalam menyempurnakan aqidah manusia pada adalah seperti Muhammad Natsir dalam bukunya fungsi dakwah perjuangan, pada ulasannya beliau menuturkan ahwah dakwah adalah usaha-usaha menyerukan dan menyampaikan kepada perorangan manusia dan seluruh umat manusia konsepsi Islam tentang pandangan dan tujuan hidup manusia di dunia ini, dan yang meliputi ammar ma'ruf nahi munkar dengan berbagai macam cara dan media yang di peroleh akhlak dan membimbing pengalamannya dalam hidup bermasyarakat dan hidup di negara. (Margono: 2007) Selain Natsir karya Quraish Shihab dalam bukunya membumikan al-Qur'an dan peran wahyu dalam 
kehidupan masyarakat, meyakini bahwah Dakwah adalah seruan atau ajakan kepada keinsyafan atau usaha mengubah situasi kepada situasi yang lebih baik dan sempurna, baik terhadap pribadi maupun masyarakat. Perwujudan dakwah bukan sekedar usaha peningkatan pemahaman dalam tingkah laku dan pandangan hidup saja, tetapi juga menuju sasaran yang lebih luas. Apalagi sekarang ini, ia harus lebih berperan menuju kepada pelaksanaan ajaran Islam secara lebih menyeluruh dalam berbagai aspek (Shihab: 2001).

Adapun beberapa tulisan atau karya Ilmiah terkait yang cukup relevan yaitu tulisan Sujarwo yang berjudul Keteladanan Dalam Pendidikan Islam Studi Tentang Keteladanan Rasulullah Muhammad dalam Bidang Pendidikan seperti yang diajarkan Rasulullah Muhammad. Saad Riyad mengungkapkan bahwa pribadi Rasulullah Muhammad adalah sosok yang memiliki kecerdasan emosi yang tinggi dalam menyikapi lawan, baik dalam keadaan menang maupun kalah. Kenyataannya, banyak yang dari lawan tersebut yang kemudian menjadi masuk Islam, bahkan menjadi pembela-pembela utamanya, beliau senantiasa berinisiatif memaafkan musuh, manakala mereka mau masuk Islam, ataupun yang tetap kafir tetapi mau menghormati Islam. Dalam pembahasan buku inilah yang mencerminkan pancaran sifat Allah al-Ghaffar dalam diri Rasulullah. (AL-Jada: 2004) Risalah Rasulullah berisi tauhid, kesamaan derajat antara manusia dan persaudaraan serta akhlak mulia. Setelah beliau menerima wahyu pertama beliau kemudian melaksanakan dakwah. Pokok ajaran yang disampaikan adalah tauhid, mengesakan Allah. Para penyembah berhala diseru untuk meninggalkan berhala. Ajaran Anthropomorphisme, yaitu suatu paham yang menyatakan Tuhan dapat menyerupai bentuk manusia adalah ajaran yang keliru. Mereka diajak untuk membersihkan dari segala macam bentuk kemusyrikan untuk mengesakan Allah. (Muhammad Haezan: 3008) Inilah tinjauan pustaka penulis dan pendapat-pendapat dari sumber buku-buku yang relevan dan membahas tentang judul penelitian konsep dakwah Rasulullah dalam menyempurnakan akhlak manusia periode Mekah. 


\section{Landasan Teori}

Secara bahasa dakwah adalah berarti memanggil, mengajak dan menyeru. (Amin: 2009) Senada dengan itu, Warson Munawwir, menyebutkan bahwa dakwah adalah Memanggil, mengundang, mengajak, menyeru, mendorong dan memohon. (Munawwir: 1994) Dakwah secara istilah dipahami mengajak orang lain untuk menyakini dan mengamalkan aqidah dan syariah Islam yang terlebih dahulu telah diyakini dan diamalkan oleh pendakwah sendiri. (Hasjmy: 1994) Sedangkan menurut Aboebakar Aceh dakwah yang berasal dari $d a^{\prime} a$ berarti Perintah mengadakan seruan kepada semua manusia untuk kembali dan hidup sepanjang ajaran Allah yang benar, dilakukan dengan kebijaksanaan dan nasehat yang baik. Kata-kata ini mempunyai arti luas sekali, tetapi tidak keluar dari tujuan mengajak manusia hidup sepanjang agama dan hukum Allah. (Aboebakar: 1996) Sebenarnya ada beberapa kata atau kalimat dalam bahasa Arab yang mempunyai makna hampir sama dengan kata dakwah. Pembendaharaan kata dalam bahasa Arab cukup banyak yang mempunyai padanan kata dakwah. (Syukir:1996) Diantaranya ialah Tabligh yang artinya Menyampaikan, yakni menyampaikan ajaran Allah dan Rasul kepada orang lain yang penyajiannya menurut apa adanya (objektif) mengemukakan fakta-fakta, tanpa adanya unsurunsur paksaan untuk diterima atau diikuti. Kemiripan selanjutnya adalah kata al-amr Bi al-Ma'ruf yang memiliki padanan kata makna memerintahkan kepada kebajikan, yaitu kebaikan yang dimaksud adalah kebaikan yang diperintahkan dalam ajaran Islam. Selanjutnya kata an-Nahy an Al-Munkar artinya yang memiliki arti melarang kepada perbuatan yang jahat atau perbuatan yang dilarang oleh agama Islam.

Selain itu, An-Nasihah Memberi petunjuk yang baik, yaitu tutur kata yang baik dalam menyampaikan pesan-pesan dakwah. Nasehat yang dimaksud adalah usaha memperbaiki tingkah laku seseorang atau sekelompok orang atau masyarakat. Selanjutnya, 
Mau'izhah artinya memberi nasehat, Al-Irsyad artinya Suatu upaya untuk mendorong manusia agar mau mengikuti petunjuk dengan menyampaikan kebenaran Islam. Sekaligus larangan-larangannya sehinggga menimbulkan perbuatan manusia untuk mengikuti Islam, $A d-D i$ 'ayah artinya propaganda yaitu upaya untuk mempropagandakan agama Islam sehingga mereka mengikuti agama Islam, Washyyah artinya memberi wasiat tentang kebenaran agama Islam, maksudnya wasiat-wasiat tentang kebenaran Agama Islam, Tabsyir artinya memberi kabar berita tentang rahmat dan karunia Allah yang akan diperoleh orang-orang yang beriman, Tadzkirah atau Indzar artinya adalah memberi peringatan atau mengingatkan manusia agar selalu menjauhkan perbuatan yang menyesatkan dan agar selalu mengingat Allah agar mengikuti pertunjuknya. Terakhir adalah kata Al-Jihad yang memiliki arti berperang atau berjuang membela agama Allah (Asmuni: 1996).

\section{Pembahasan}

Pada umumnya dakwah merupakan upaya praktis sebagai aspek penting dalam penyebaran Islam, dalam menyoroti aktivitas ini, penyampaian pesan dakwah dapat dikelompokan kedalam beberapa aspek dalam ilmu dakwah seperti Dakwah bi Al-Lisan yang dikenal sebagai dakwah yang dilaksanakan melalui tutur kata, yang umumnya aktiitas ini dilakukan dengan cara melakukan ceramah, khutbah, diskusi, maupun nasehat nasehat.

(Amin, 2009:99). Metode ceramah ini, tampaknya sudah sering dilakukan oleh aktivis dakwah, baik melalui ceramah di Majlis Taklim, khutbah jum'at di masjid-masjid maupun ceramah yang dilakukan pada acara pengajian-pengajian. Dari aspek jumlah barangkali dakwah melalui lisan ini sudah cukup banyak dilakukan oleh para juru dakwah di tengah-tengah masyarakat. Selain itu adalah Dakwah bi Al-Hal yang merupakan Dakwah yang dilakukan dengan perbuatan praktis yang meliputi keteladanan (Amin, 2009:99). Misalnya, dengan tindakan amal karya nyata yang dari dari karya nyata tersebut hasilnya dapat dirasakan secara konkret oleh masyarakat sebagai objek dakwah. Jenis selanjutnya adalah Dakwah bi Al-Qolam yaitu dakwah yang di implementasikan melalui sebuah tulisan yang dilakukan dengan keahlian menulis seperti melalui 
Artikel Ilmiah dikalangan akademis, surat kabar, majalah, buku, maupun pada ruang internet (Amin, 2009:99). Beberapa analisis menyatakan bahwah berdasarkan jangkauan yang dapat dicapai oleh aktiitas menulis pesan yang mengandung nilai Islam ini lebih luas daripada Implementasi lisan, terlebih metode yang digunakan tidak membutuhkan waktu secara khusus dalam progres kegiatannya.

Jenis selanjutnya Dakwah Bil Hikmah, yaitu aktivitas dengan menggunakan dalil atau argumentasi yang qath' $i$ dan memiliki nilai kemanfaatan terhadap sosial maupun lingkungan Eksternal(Amin, 2009:98). Didalam kaidah ilmu dakwah, hikmah dipahami sebagai suatu metode pendekatan melalui komunikasi dilaksanakan atas dasar persuasif. Dengan demikian, dapat termenologi hikmah yang dimaksud adalah mengajak manusia menuju jalan Islam tidak terbatas pada perkataan lembut, memberi semangat, sabar, ramah, dan lapang dada, tetapi juga tidak melakukan sesuatu melebihi ukurannya, dengan kata lain aktivitas yang dilakukan harus menempatkan sesuatu pada tempatnya. Selain itu ada juga jenis Dakwah dengan ucapan yang mengandung nasihat-nasihat baik dan bermanfaat bagi lingkungan yang mendengarkannya, atau argumen-argumen yang memuaskan sehingga pihak audiensi dapat membenarkan apa yang disampaikan oleh subjek dakwah (Amin, 2009:99). Terakhir ialah Dakwah dengan Mujadalah yaitu aktivitas dakwah yang di implementasikan melalui berdiskusi dengan cara yang baik dari caracara berdiskusi yang ada. Oleh karna ini, beberapa pandangan menyatakan bahwah dakwah mujadalah merupakan cara terakhir yang digunakan untuk berdakwah yang digunakan untuk orang-orang yang taraf berfikirnya cukup maju, dan kritis seperti ahli kitab yang telah memiliki bekal keagamaan dari utusan sebelumnya.

Awal proses terbentuknya Darus Islam yang pertama di muka bumi saat itu, di samping juga merupakan pernyataan berdirinya negara Islam di bawah pimpinan pendirinya yang pertama Muhammad. Karena itu, pekerjaan yang pertama dilakukan Muhammad ialah meletakkan azaz penting bagi negara. Azaz tersebut, tercermin pada tiga aspek penting yang meliputi pembangunan Masjid, Mempersaudaraan sesama kaum muslimin secara umum serta antara kaum Muhajirin dan kaum Anshar secara khusus, dan membuat perjanjian yang mengatur kehidupan sesama kaum muslimin dan menjelaskan hubungan mereka dengan orang- 
orang luar Islam secara umum dengan kaum Yahudi. Dalam sejarah mencatat bahwah kejadian unta tunggangan Rasulullah berhenti di suatu tempat yang berujung pada kondisi nabi memerintahkan agar di tempat itu dibangun sebuah masjid adalah titik nadi perluasan dakwah Islam dijazirah Arab. Upaya pendirian masjid, juga melibatkan muhammad secara langsung untuk ikut serta dalam proses pembangunannya hingga mengangkat dan memindahkan batu-batu masjid dengan tangannya sendiri merupakan cerminan kondisi dan hubungannya terhadap pengikut maupun sosial masyarakat dimadinah (Ramadhan: 1999).

Pemanfaatan masjid sebagai pusat keagamaan, membuat umat Islam kala itu senantiasa melakukan berbagai aktivitasnya baik sebagai tempat ibadah, belajar memutuskan perkara mereka, berjual beli, maupun perayaan-perayaan (Ahmad Al-Usairy: 2011). Tempat ini menjadi faktor yang mendekatkan di antara mereka. Beberapa catatan menjelaskan bahwah Masjid Rasulullah dengan bentuknya yang asli, tanpa penambahan atau pemugaran, hanya bertahan sampai akhir masa Khalifah Abu Bakar. Karna pada masa Khilafah Umar, mengalami sedikit perbaikan maupun renovasi, meskipun bentuk arsitektur bangunannya masih seperti aslinya. Beberapa indikasi keberhasilan dakwah yang dilakukan adalah upaya Muhammad dalam mempersaudarakan dua kelompok popular yaitu kaum Muhajirin dan Anshar atas dasar kebenaran dan rasa persamaan. Mereka bahkan dipersaudarakan untuk mewarisi sepeningal mereka sehingga pengaruh ukhuwah Islamiyah lebih kuat dan membekas daripada pengaruh ikatan darah. Rasulullah Muhammad berhasil mempersaudarakan Ja'far bin Abu Thalib dengan Mu'adz bin Jabal, Hamzah bin Abdul Mutthalib dengan Zaid bin Haritsah, Abu Bakar As-Shiddiq dengan Kharijah bin Zuhair, Umar Ibnul Khathab dengan Uthbah bin Malik, Abdur-Rahman bin A'uf dengan Sa'ad bin Rabi' dan seterusnya (Al-Buthy: 2011).

Lebih jauh, Muhammad Rasulullah berhasil mengikat persaudaraan antara para sahabat ini dengan suatu kerangka umum berupa ukhuwah dan muawalah atau penyerahan loyalitas, persaudaraan yang dibangun didasarkan pada prinsip marterial, di antaranya ialah ditetapkan prinsip saling mewarisi sesama mereka. Rasulullah mempersaudarakan di antara kaum muslimin. Mereka kemudian membagikan rumah yang mereka miliki maupun harta kekayaan. Barangkali inilah alasan bahwah banyak para peminat 
sejarah keislaman memahami fenomena ini sebagai persaudaraan yang terjadi lebih kuat daripada hanya persaudaraan yang berdasarkan keturunan. Dengan persaudaraan ini, Muhammad dalam perjalanannya telah berhasil menciptakan sebuah kesatuan yang berdasarkan agama sebagai penganti dari persatuan berdasarkan kabilah. Ikatan-ikatan persaudaraan ini tetap didahulukan daripada hak-hak kekeluargaan sampai terjadi perang Badar Kubra ( Al-Buthy: 2011).

Dalam menjalani tugas dakwah, muhammad berhadapan dengan Masyarakat Jahiliyah yang telah menjadi tradisi bagi kalangan umum masyarakat Arab yang menyakini adanya banyak Politeisme. Jika kita menyoroti dalam perspektif sejarah, menunjukan bahwah masyarakat Arab di Mekah dari berbagai macam khurajat dan kepercayaan yang bertentangan dengan misi Islam. Kemudian, berkat perjuangan Rasulullah mentauhidkan Allah atau mengimani adanya Allah, Dzat yang maha esa. mentauhidkan yakni sikap mengesakan Allah dengan sepenuh hati, tidak menyekutukan-Nya, hanya mengabdi, memohon, dan meminta pertolongan kepada Allah (Departemen Agama: 2013). Dalam bidang hukum dan moral Muhammad telah berhasil memperbaiki kondisi sosial Masyarakat yang pada saat itu adalah masyarakat yang umumnya jauh dari masyarakat yang menghargai kemanusiaan, ketidakadilan, dan berbagai kondisi memprihatinkan. Dengan demikian, perubahan yang dilakukan oleh Rasulullah ini sangat signifikan dan sangat berpengaruh bagi kehidupan manusia sampai saat ini. Bahkan, beliau juga berhasil mendirikan suatu negara Madinah yang kelak kemudian hari menjadi satu kekuatan politik yang menjadi kiblat peradaban Islam. Rasulullah berhasil mengajak masyarakat untuk meyakini dan mempercayai, dan beriman akan datangnya hari Qiyamat. Karena dengan adanya kepercayaan akan hari Qiyamat membuat masyarakat menjalani kehidupan sesuai denga apa yang diajarkan Rasulullah karena setiap perbuatan pasti akan mendapat balasan sekecil dan sebesar apapun perbuatan itu.

Kunci keberhasilan dakwah Nabi Muhammad dalam mengembangkan ajaran Islam terletak pada sikap dan perilaku dalam mengemban fungsi kerisalahannya. Sikap-sikap yang perlu diteladani mencakupi aspek kelembutan, Kebenaran yang pada asalnya susah untuk diterima oleh jiwa, ketika disampaikan dengan cara yang buruk, 
cara yang kasar, tentunya justru akan membuat orang semakin lari dari kebenaran. Oleh karena itulah, Rasulullah Muhammad menyampaikan dakwah dengan cara lemah lembut. Sikap tersebut di dalam berdakwah mempunyai banyak sekali faidah. Salah satu di antaranya adalah dapat menyadarkan orang-orang yang telah terjerumus dalam perbuatan dosa dan maksiat. Selain itu, konsistensi dalam misi, Rasulallah berhasil dalam berdakwah dan berjuang, karena beliau mampu meninggalkan perbuatan-perbuatan dosa. Kalau beliau melarang orang lain untuk berbuat jahat, maka beliau menjadi pelopor untuk meninggalkan perbuatan jahat. Kalau beliau melarang larang lain untuk korupsi, maka beliau menjadi pelopor untuk meninggalkan korupsi. Kalau beliau melarang orang lain untuk berjudi, maka beliau menjadi pelopor untuk meninggalkan perjudian. Karena beliau konsekuen terhadap apa yang beliau ajarkan, maka beliau menjadi orang yang berhasil dalam dakwahnya (Amin: 2009).

Selain daripada itu kunci keberhasilan Rasulallah terletak pada sikap iklas tanpa mengharapkan imbalan jasa apapun baik harta, tahta, wanita semuanya perjuangan dakwah ditandaskan pada perjuangan risalah Islam. Untuk berhasil dalam berjuang, hendaklah sabar dalam menghadapi berbagai kendala yang akan menghambat perjuangan umat Islam. Rasulallah berhasil dalam berjuang, tentu beliau menghadapi musuh-musuh Islam. Bahkan beliau dilempari batu oleh orang-orang tha'if, tetapi beliau sabar dan berdo'a, Karena kebesaran hati Rasulallah, walaupun mengalami distorsi sosial seperti dilampari batu, tetapi beliau tetap bersabar. Rasulullah selalu bersabar dalam menghadapi perjuangan dakwahnya, baik musibah, ujian, derita, rintangan dan perlakuan-perlakuan orang-orang Qurasy menghalang-halangi dakwah terhadapnya semua itu dihadapi dengan sabar. Cerminan kesabaran bisa kita lihat pada pembunuhan karib kerabat, penyerangan oleh para musuhnya, dan kesabaran telah menjadi baju besinya, perisainya, sahabat dekatnya dan kekasihnya, setiap kali ucapan para musuhnya mengguncangkannya.

\section{Simpulan}

Dari beberapa ulasan maupun uraian pada tulisan sebelumnya yang telah dikemukakan pada pemahasan sebelumnya secara garis besar dapat diambil kesimpulan bahwa:

Pertama, strategi Dakwah Rasulullah SAW yaitu menggunakan dakwah bil Hikmah, dengan Ma'uizhah Hasanah, 
dengan Mujadalah, dakwah dengan lisan, dakwah dengan perbuatan, dakwah dengan tulisan dalam menyempurnakan aqidah manusia.

Kedua, Rasulullah merupakan seorang rasul yang diutus Allah untuk menyempurnakan aqidah dan akhlaq manusia. Biografi Rasulullah yaitu mulai dari nasabnya, kelahirannya, masa Rasulullah SAW kanak-kanak dalam asuhan kakeknya, pamannya kemudian remaja, perniagaan dengan harta Khadijah dan pernikahannya, membangun Ka'bah, Rasulullah SAW menyendiri ke Gua Hira, dan sakit wafatnya Rasulullah SAW.

Ketiga, Implementasi keberhasilan Dakwah Rasulullah dalam mentranspormasi nilai Islam pada poros tradisi Jahiliyah yaitu berkat kegigihannya dalam perjuangan dakwah, yang telah mengorbankan tenaga, waktu, fikiran, harta dan semuanya untuk menegakkan kebenaran. Maka banyaknya perubahan-perubahan di bidang aqidah, hukum dan Syariah, akhlaq. Semua itu berhasil karna ada pertolongan Allah SWT dan Rasulullah mempunyai kepribadian-kepribadian yang terpuji sesuai antara perbuatan dan ucapan, pemberani, meninggalkan perbuatan dosa dan maksiat, memiliki keikhlasan memilki kesabaran dalam berdakwah sebagai pemimpin umat dan pemimpin agama melawan musuh-musuhnya. 
114 Wawan Sopiyan, Muklis, Solimin, Analisis Akulturasi ,....

\section{DAFTAR PUSTAKA}

Al-Buthy, Muhammad Sa'id Ramadhan1999. Sirah Nabawiyah, Analisis Ilmiah Manhajiah Sejarah Pergerakan Islam di Masa Rasulullah SAW, Robbani Press, Jakarta.

Aceh, Aboebakar 1986. Potret Dakwah Rasulullah SAW dan Para Sahabatnya, Ramadhani, Solo

Al-Usairy, Ahmad 2011, Sejarah Islam Sejak Nabi Adam hingga Abad XX, Akbar Media, Jakarta.

Eko Nopriyansa, (2019) Analisis Teks Bible dan Al-Qur'an dalam Menjelaskan Sejarah Kenabian, Jurnal WARDAH Vol.20 No.2.

Eko Nopriyansa, (2020) The Miniature Of God And The Termenology OF The Bible Text From The Islam Perspective, Jurnal Diskursus Islam Vol.8 No.1.

Harton, B. Paul, L. Hunt, Chester. 1990. Sosiologi Jilid 2. Jakarta: Erlangga

Nopriyansa, Eko, (2019) Islamic Perspective on Syaifudin Ibrahim's Priester (Analysis Of The Views, Assumptions And Challenges Of The Reverend Syaifuddin Ibrahim Against Muslims), Jurnal Ilmu Ushuluddin Vol.6 No.1.

Haezan, Muhammad 2008 "Dakwah Rasulullah Menurut History Islam (Periode Mekah- Madinah), Skripsi Sarjana S.1 Program Studi Komunikasi Penyiaran Islam Jurusan Dakwah dan Komunikasi Sekolah Tinggi Agama Islam Negeri, Surakarta.

Hasjmy, A 1884, Dustur Dakwah Menurut Al-Qur'an, Bulan Bintang, Jakarta

Helmy, Masdar 1973, Dakwah Dalam Alam Pembangunan Jilid I dan II. Toha Putra, Semarang. 
Irawan, Prasetya 1999. Logika dan Prosedur Penelitian, STIA-LAU Pres, Jakarta.

Margono, S 2007. Metodologi Penelitian Pendidikan, Rineka Cipta, Jakarta

Munawwir, Warson 1994, Kamus Munawwir, Pustaka Progresif, Jakarta

Munir Amin, Samsul 2009. Ilmu Dakwah, Amzah, Jakarta

Muriah, Siti 2000. Metodologi Dakwah Kontemporer. Mitra Pustaka, Yogyakarta.

Natsir, M. 1996. Fungsi Dakwah Perjuangan, dalam Abdul Munir Mulkhan, Ideologi Gerakan Dakwah, Sipres, Yogyakarta.

Omar Toha, Yahya 1992. Ilmu Dakwah. Wijaya, Jakarta

Shihab, Quraish 1999. Wawasan Al-Qur'an, Mizan, Bandung.

Syukir, Asmuni 1983. Strategi Dakwah Islam, Usahan Nasional, Surabaya

Taimiyah, Ibnu 1983. Al-Muntaqa min Akhba Al-Musthafa, Jilid II, Riyadh. 